\title{
Recepcija del Draga Jančarja na Češkem
}

Iveta Bůžková

Filozofska fakulteta Masarykove univerze v Brnu

Faculty of Arts, Masaryk University in Brno

iveta.buzkova@gmail.com

Prispevek se osredotoča na prevode Draga Jančarja v češčino. V prvem delu so predstavljeni češko-slovenski kulturni in predvsem literarni odnosi in najpomembnejši prevajani avtorji. Drugi del govori o obdobju po letu 1991, ko se ponovno razvija češko-slovensko literarno sodelovanje. Tretji del je namenjen prevodom in recepciji Draga Jančarja na Češkem.

Ključne besede: češko-slovenski literarni odnosi, češko-slovenski prevodi, Drago Jančar

Reception of Drago Jančar in the Czech Republic

The article focuses on a translation of the works of Drago Jančar into Czech. The first part describes Czech-Slovene cultural and literary relations and the most important translated authors. The second part speaks about the period after 1991 when CzechSlovenian relations started to envolve again. The third part is dedicated to the translation and reception of Drago Jančar in the Czech Republic.

Key words: Czech-Slovenian literary relationships, CzechSloveninan translations, Drago Jančar 


\section{Češko-slovensko literarno sodelovanje $\mathrm{e}^{\mathrm{I}}$}

Češko-slovenski kulturni stiki so bili ves čas tesnejši kot na primer češko-srbski ali češko-hrvaški. Slovenci so več let, podobno kot Čehi, pripadali Avstro-Ogrski in imajo del skupne zgodovine. Češka kultura je pomembno vplivala na razvoj slovenske umetnosti in književnosti, predvsem v 19. stoletju. Kot češko-slovensko literarno sodelovanje lahko razumemo poročila o književnem življenju in prevode literarnih del, izdanih knjižno, $\mathrm{v}$ revijah ali v časopisih. Tradicija češko-slovenskega kulturnega in literarnega sodelovanja sega že v 16 . stoletje, do revolucije in pomladi narodov leta 1848 se je začela živahna prevajalska dejavnost. Petr Mainuš je češko-slovenske literarne stike zaradi preglednosti razdelil v šest obdobij: 1. obdobje (1882-1918), 2. obdobje med vojnama (1918-1940), 3. obdobje po drugi svetovni vojni (1946-1948), 4. pasivno obdobje (1949-1956), 5. obdobje popuščanja medsebojnih odnosov (1957-1989) in 6. obdobje od let 1990/1991 dalje (Mainuš 2005).

Intenzivni medsebojni češko-slovenski literarni stiki se začenjajo leta $1832 \mathrm{~s}$ prvim prevodom najbolj znanega slovenskega pesnika Franceta Prešerna, ki ga je prevedel F. L. Čelakovský. Leta 1882 je bil izdan prevod besedila Tugomer Josipa Jurčiča in Vladimirja Levstika, največ pa so prevajali Ivana Cankarja, Zofko Kveder, Frana Govekarja, Frana Erjavca ali Ivana Tavčarja (Mainuš 2005). Kot opozarja Oton Berkopec, je veliko (tudi poznejših) prevodov neberljivih zaradi zastarelosti pa tudi zaradi okornosti, ki je posledica nezadostnega znanja slovenskega jezika. Pogosto so tudi prevajali besedila manj pomembnih avtorjev z nizko umetniško ravnjo, ki pa so imeli osebne stike s prevajalci (Berkopec 1956, 237-238). Na slovenski strani so delovali prevajalci kot Alojzij Benkovič, Fran Gestrin, Leopold Gorenjec, Jože Debevec, Ivan Tomšič ali France Tomšič, na Češkem pa že prevajalci z jezikovno izobrazbo, ki so študirali slavistiko na Dunaju ali v Pragi, na primer knjižničar univerzitetne knjižnice v Pragi Jaromír Borecký, urednik revije Slovanský přehled Adolf Černý, Josef Penížek in mnogi drugi (Mainuš 2005).

Obdobje med vojnama lahko označimo kot zlato obdobje medsebojnih literarnih odnosov, ko je poraslo število prevodov, predvsem na Čehoslovaškem. Prevajana so bila literarna dela Ivana Cankarja, Vladimirja Levstika, Frana Saleškega Finžgarja, Ivana Tavčarja in Ivana Preglja. V slovenščino so prevajali avtorje, kot so bili Marie Majerová, Ivan Olbracht, 
Jiří Wolker ali Karel Čapek. Do konca aktivnega medsebojnega sodelovanja je prišlo z začetkom druge svetovne vojne. Po drugi svetovni vojni se je ponovno povečalo število prevodov v obeh državah. Prevedeno je bilo skupaj šestintrideset jugoslovanskih knjig, od tega trinajst iz slovenščine, na primer Ivan Cankar, Ivan Tavčar, Prežihov Voranc, Tone Seliškar in Vladimir Bartol (Mainuš 2005).

Razcvet sodelovanja je nasilno prekinil razkol med Jugoslavijo in ZSSR. V letih 1949-1953 torej iz političnih razlogov ni izšel noben prevod slovenske (in tudi srbohrvaške) literature. $V$ šestdesetih letih je s praško pomladjo nastopila renesansa medsebojnih literarnih odnosov. Spet se prevajajo klasiki kot Ivan Cankar, pa tudi Srečko Kosovel, France Bevk ali Oton Župančič. V slovenščino so bile prevedene knjige čeških avtorjev, na primer Jaroslava Seiferta, Karla Čapka, Jaroslava Haška ali Josefa Škvoreckega (Šnytová 2014, 457-461).

Po padcu komunizma na Čehoslovaškem leta 1989 in izjavi samostojne Slovenije leta 1991 je prišlo do ponovnega razvoja medsebojnih političnih, kulturnih in literarnih odnosov, ki so se navezali na tradicijo zgodovinskega sodelovanja obeh držav.

\section{Češko-slovenski prevodi po letu 1991}

Kot smo že omenili, se po političnih spremembah na začetku devetdesetih let ponovno razvijajo tudi češko-slovenski literarni odnosi. V zadnjih letih je izšlo pet antologij slovenske poezije, dve antologiji kratke proze (Promlky času, Vně hranic) in antologija slovenske drame. Poleg antologij izhaja veliko prevodov slovenskih del, največje število v letih 2004-2005, ko je bilo izdano deset knjig. Veliko število prevodov iz slovenščine izhaja s pomočjo subvencij slovenskih institucij, na primer Društva slovenskih pisateljev (Trubarjev sklad) ali Centra za slovenščino kot drugi/tuji jezik, ki financira lektorate slovenščine na tujih univerzah. Slovenske knjige na Češkem izdajajo na primer založbe Větrné mlýny, Kniha Zlín, Host, Mladá fronta, Volvox Globator, Dauphin in druge (Kozár 2011, 189-198).

Pomembno vlogo pri izbiri izdanih del igrajo osebni stiki čeških prevajalcev in slovenskih pisateljev. Najbolj prevajani avtor je Drago Jančar; sledijo mu Aleš Debeljak, Žarko Petan, Andrej Skubic, Tomaž Šalamun, Goran Vojnovič in drugi. Za razliko od predhodnih obdobij so zastopani avtorji vseh generacij, torej klasiki slovenske literature (Ivan Cankar, Vladimir Bartol, Edvard Kocbek), starejši avtorji (Žarko Petan), avtorji srednje gener- 
acije (Aleš Debeljak, Alenka Jensterle Doležal) do mlajše generacije (Suzana Tratnik, Goran Vojnovič, Dušan Čater) (Kozár 2011, 189-198).

Od sedemdesetih let 20. stoletja je najplodovitejši prevajalec iz slovenščine literarni kritik František Benhart (1924-2006), ki je izrazito vplival na recepcijo slovenske literature na Češkem. Prevedel je dvainsedemdeset knjig, številne pesmi in drame ter je bil glavni prevajalec Draga Jančarja in Aleša Debeljaka. V devetdesetih letih se uveljavljajo tudi mladi prevajalci - zlasti absolventi slovenistike na Karlovi Univerzi v Pragi (od leta 1993), Masarykovi univerzi v Brnu (od leta 1995) ali Univerzi v Pardubicah (od leta 2007). Med njimi na primer Petr Mainuš, Libor Doležán, Aleš Kozár, Radek Novák, Hana Chmelíková-Mžourková, Alena Šamonilová, Kristina Pellarová, Kamil Valšík, Martina Šaradínvá, Pavel Šaradín in drugi (Przybylski 2011, 229-239). Iz starejše in srednje generacije je treba še omeniti Ivana Dorovskega, Milado Nedvědovo, Alenko Jensterle-Doležal, Jano Špidurovo in Davida Blažeka.

\section{Prevodi Draga Jančarja v češčino}

Drago Jančar sodi med najbolj znane in najbolj prevajane slovenske avtorje. Je pisatelj, avtor krajše proze, esejist, pa tudi dramatik. Njegova dela so bila prevedena $\mathrm{v}$ več kot 20 jezikov, največkrat $\mathrm{v}$ nemščino, češčino in hrvaščino. $V$ češkem prevodu so izšli njegovi štirje romani, dve knjigi kratke proze, drama in veliko esejev. Leta 1990 je bil izdan prevod njegovega romana Galjot (v češčini Galejník), ki ga je prevedel František Benhart. ${ }^{2}$ Galjot žanrsko sodi predvsem na področje zgodovinskega romana, vsebuje tudi nekatere nastavke modernističnega ali postmodernističnega romana, pomembno vlogo ima zlasti metafora. Leta 1999 je izšel avtobiografski roman Posmehljivo poželenje, $\mathrm{v}$ češkem prevodu Františka Benharta pod nazivom Chtíč chtíc nechtíc. O jiném rozumění; kraj dogajanja je v ZDA. ${ }^{3}$ Leta 2003 je bil izdan Jančarjev roman Katarina, pav in jezuit, v češčini Kateřina, páv a jezuita; spet v prevodu Františka Benharta. Gre za zgodovinski roman, ki opisuje ljubezensko razmerje med nekdanjim jezuitom, oskrbnikovo hčer Katarino in stotnikom Windischem (pavom). ${ }^{4}$ Doslej zadnji roman Severni sij je izšel leta 2009 pod nazivom Polární záře v prevodu Libora Doležána. Roman se dogaja v Sloveniji pred drugo svetovno

\footnotetext{
2 Jančar, Drago. 1990. Galejník. Praha: Odeon.

3 Jančar, Drago. 1999. Chtíc chtíč nechtíc. Praha: Volvox Globator.

4 Jančar, Drago. 2002. Kateřina, páv a jezuita. Praha: Paseka.
} 
vojno. Leta 1995 je izšel izbor kratke proze iz Jančarjevih knjig Smrt pri Mariji snežni, Pogled Angela, Augsburg in druge resnične pripovedi, v prevodu Františka Benharta kot Pohled anděla. ${ }^{6}$ Leta 2003 so bile pod nazivom Př́zrak $z$ Rovenské izdane novele iz knjig Pogled Angela in Prikazen iz Rovenske, spet v prevodu Františka Benharta. Benhart je tudi prevedel do sedaj edino v češčino prevedeno Jančarjevo dramo Halštat (2000, z istim naslovom). ${ }^{7}$ Prevedeni so bili tudi nekateri eseji, na primer Př́běh, který můžete zaspat iz knjige Duša Evrope (2007, prevod Petr Mainuš), Brioni: eseje (2005, prevod František Benhart, Hana Chmelíková in David Blažek) ${ }^{8}$ in Přičky z Jákobova žebříku (izbor esejev, prevod Petr Mainuš).

Kakor je bilo že omenjeno, je imel František Benhart izrazit vpliv na recepcijo slovenske literature na Češkem. Bralci na Češkem so se lahko seznanili z Jančarjevimi deli skoraj samo skozi njegove prevode vse do njegove smrti. Ko govorimo o recepciji Draga Jančarja na Češkem, moramo poudariti recenzije čeških literarnih kritikov. Najpogosteje jih pišejo že omenjeni češki slovenisti, na primer Aleš Kozár, Libor Doležán, Hana Chmelíková, Kamil Valšík, Petr Mainuš, ki so hkrati tudi avtorji Jančarjevih prevodov. Na eni strani gre za strokovnjake, ki dobro poznajo slovenščino in kulturni politični kontekst Jančarjevih del, na drugi strani pa ne moremo govoriti o popolnoma objektivnem pogledu.

\section{Seznam prevodov Draga Jančarja v češčino}

\section{ROMANI}

Galejník (1990) - Galjot (1978), prevod František Benhart

Chtíč chtíc nechtíc. O jiném rozumění (1999) - Posmehljivo poželenje (1993), prevod František Benhart

Kateřina, páv a jezuita (2003) - Katarina, pav in jezuit (2000), prevod František Benhart

Polární záře (2009) - Severni sij (2005), prevod Libor Doležán

5 Jančar, Drago. 2009. Polární záře. Praha: H+H, 2009.

6 Jančar, Drago. 1995. Pohled anděla. Praha: Volvox Globator.

7 Jančar, Drago. 2003. Př́zrak z Rovenské. Brno: Host; Jančar, Drago. 200o. Halštat. Praha: Divadelní ústav.

8 Jančar, Drago. 2005. Brioni. Praha: Volvox Globator.

9 Jančar, Drago. 2006. Příčky z Jákobova žebříku. Brno: CDK. 
Dnes v noci jsem ji viděl (2018) - To noč sem jo videl (2010), prevod Kamil Valšík

\section{KRATKA PROZA}

Pohled anděla (1995) - Pogled angela (1992), izbor iz knjig Smrt pri Mariji Snežni, Pogled angela, Augsburg in druge resnične pripovedi, prevod František Benhart

Př́źzak z Rovenské (2003) - Prikazen iz Rovenske (1998), novele iz knjig Pogled angela in Prikazen iz Rovenske, prevod František Benhart

\section{DRAMA}

Halštat (2000) - Halštat (1994), prevod František Benhart

\section{ESEJI}

Příběh, který můžete zaspat (iz knjige Duša Evrope, 2007), prevod Petr Mainuš

Brioni: eseje (2005) - Brioni: eseji in drugi zapisi (2003), prevod František Benhart, Hana Chmelíková, David Blažek

Příčky z Jákobova žebř́íku (2006) - Klini z lestve sv. Jakoba (izbor esejev), prevod Petr Mainuš

\section{REVIJALNE OBJAVE}

Vzpomínky na Jugoslávii (1991) - Spomini na Jugoslavijo. In: Lettre internationale, 1991, č. 28, s. 32-38, prevod František Benhart

Zjevování v prosinci (1991) - Prikazovanje. In: Literární noviny, 1991, roč. 2, č. 50, s. 10, prevod František Benhart

Zpráva z vysněné země - vidina a skutečnost (1992) - Poročilo iz devete dežele - privid ali resničnost. In: Lettre internationale, 1992, č. 7, s. 22-24, prevod František Benhart

Zjevování v prosinci (1992) - Prikazovanje. In: Lettre internationale, 1992, č. 8, s. 4-5, prevod František Benhart

Smrt u Panny Marie Sněžné (1992) - Smrt pri Mariji Snežni. In: Revue otevřené kultury, 1992, roč. 3, č. 6, s. 58-64, prevod František Benhart

Rozbitý džbán (1992) - Razbiti vrč. In: Svět a divadlo, 1992, č. 4, s. 76-80, prevod František Benhart

Špiclování Godota (1992) - Zalezujoč Godota. In: Svět a divadlo, 1992, č. 4, s. 81-107, prevod František Benhart 
Augšpurk (1993/1994) - Augsburg. In: Lettre internationale, 1993/1994, č. 11, s. 1-2, prevod František Benhart

Vztahy, především nebezpečné (1994) - Razmerja, predvsem nevarna. In: Lettre internationale ,1994, č. 12, s. 25-26, prevod František Benhart

Zapomínání znamená nové násilí (1994) - Pozaba pomeni novo nasilje. In: Scriptum, 1994, roč. 4, č. 14, s. 59-62, prevod František Benhart

Ultima creatura (1995) - Ultima creatura (fragment). In: Denní telegraf, 1995, roč. 4, č. 169, př́l. Telegraf na neděli (22. 7. 1995), prevod František Benhart

Egyptské hrnce masa (1995) - Egiptovski lonci mesa. In: Souvislosti, 1995, roč. 6, č. 2, s. 100-118, prevod František Benhart

Konec tisíciletí, účet století (1995) - Konec tisočletja, račun stoletja. In: Tvar, 1995, roč. 6, č. 11, s. 16-17, prevod František Benhart

Křídla nad Panevropou (1995) - Krila nad Panevropo. In: Tvar, 1995, roč. 6, č. 11, s. 17, prevod František Benhart

Volání a kapky (1997) - Klici in kaplje. In: Souvislosti, 1997, roč. 8, č. 1, s. 23 26, prevod František Benhart

Neděle v Oberheimu (1997) - Nedelja v Oberheimu. In: Souvislosti, 1997, roč. 8, č. 1, s. 201-203, prevod František Benhart

Prodloužená minulost (1998), izbor esejev, prevod František Benhart

Poeta a atlet (1998) - Dvanajsto poglavje: Poet in atlet (fragment iz knjige Posmehljivo Poželenje), Proglas, 1998, roč. 9, č. 8, s. 27-29, prevod František Benhart

Brioni (2001) - Brioni. In: Právo, př́l. Salon, 2001, roč. 11, č. 120, s. 4-5, prevod František Benhart

Herodes a pastýř (2002) - Herodež in pastirc. In: Vně hranic. Antologie současné slovinské krátké prózy, prevod Aleš Kozár

Střední Evropa - idea minulosti? (2002) - Srednja Evropa - ideja preteklosti? In: Host, 2002, roč. 18, č. 5, s. 42-43, prevod František Benhart

Joyceův žák (2002) - Joyceov učenec. In: Host, 2002, roč. 18, č. 5, s. 55-58, prevod František Benhart

Vzpoura čtenářů (2002) - Upor bralcev. In: Tvar, 2002, roč. 13, č. 6, s. 6-7, prevod František Benhart

Savana (2003) - Savana. In: Promlky času. Antologie slovinských povídek, 2003, prevod František Benhart

Žert, ironie a hlubší význam (2004) - Šala, ironija in globlji pomen. In: Host, 2004, roč. 20, č. 5, s. 84-90, prevod Hana Chmelíková 
Anděl ho neopustil (2004) - Angel ga ni zapustil. In: Literární noviny, 2004, roč. 15, č. 26, s. 14, prevod František Benhart

Svůdce (2005) - Zapeljivec. In: Host, 2005, roč. 21, č. 9, s. 72-74, prevod František Benhart

Dva snílkové: První stránka (2006) - Dva sanjača. In: Tvar, 2006, roč. 17, č. 4, s. 18-19, prevod František Benhart

Viri

Jančar, Drago. 1990. Galejník. Praha: Odeon.

Jančar, Drago. 1995. Pohled anděla. Praha: Volvox Globator.

Jančar, Drago. 1999. Chtíc chtíč nechtíc. Praha: Volvox Globator.

Jančar, Drago. 200o. Halštat. Praha: Divadelní ústav.

Jančar, Drago. 2002. Kateřina, páv a jezuita. Praha: Paseka.

Jančar, Drago. 2003. Př́izrak z Rovenské. Brno: Host

Jančar, Drago. 2005. Brioni. Praha: Volvox Globator.

Jančar, Drago. 2006. Příčky z Jákobova žebříku. Brno: CDK.

Jančar, Drago. 2009. Polární záře. Praha: H+H, 2009.

Literatura

Berkopec, Oton. 1956. Bilance deseti let. Slovanský přehled 42 (7): 237-238.

Iliteratura.cz. <http://www.iliteratura.cz/Fulltext?Fulltext=jan\%C4\%8Dar $>$. (Dostop 15. 7. 2017.)

Kozár, Aleš. 2011. Překlady ze slovinské literatury posledních dvaceti let $\mathrm{v}$ českém kulturním kontextu. Vzájemným pohledem - V očeh drugega, ur. Alenka Jensterle-Doležal. 189-198. Praha: NK.

Mainuš, Petr. 2005. Bibliografie knižních překladů slovinské literatury do češtiny. Lublaň: Centrum pro slovinskou literaturu.

Przybylski, Michal. 2011. Slovinští autoři v českém prostředí. Překlady ze slovinské literatury po roce 1989: stav, proměna a neuralgické body. Vzájemným pohledem - V očeh drugega, ur. Alenka Jensterle-Doležal, s. 229-239. Praha: NK.

Šnytová, Jana. 2014. Prevodi slovenske književnosti v češčino od leta 1945 do sodobnosti. V Obdobja 33: Recepcija slovenske književnosti, ur. Alenka Žbogar. 457-461. Ljubljana: Filozofska fakulteta.

Vinkler, Jonatan. 2006. Posnemovalci, zavezniki in tekmeci. Češko-slovenski in slovensko-češki kulturni stiki v 19. stoletju. Koper: Annales. 